\title{
Pulsed-light system as a novel food decontamination technology: a review
}

\author{
N. Elmnasser, S. Guillou, F. Leroi, N. Orange, A. Bakhrouf, and M. Federighi
}

\begin{abstract}
In response to consumer preferences for high quality foods that are as close as possible to fresh products, athermal technologies are being developed to obtain products with high levels of organoleptic and nutritional quality but free of any health risks. Pulsed light is a novel technology that rapidly inactivates pathogenic and food spoilage microorganisms. It appears to constitute a good alternative or a complement to conventional thermal or chemical decontamination processes. This food preservation method involves the use of intense, short-duration pulses of broad-spectrum light. The germicidal effect appears to be due to both photochemical and photothermal effects. Several high intensity flashes of broad spectrum light pulsed per second can inactivate microbes rapidly and effectively. However, the efficacy of pulsed light may be limited by its low degree of penetration, as microorganisms are only inactivated on the surface of foods or in transparent media such as water. Examples of applications to foods are presented, including microbial inactivation and effects on food matrices.

Key words: pulsed light, decontamination technology, microorganism, foods, review.

Résumé : En réponse aux préférences du consommateur pour avoir des aliments de haute qualité s'approchant le plus possible du produit frais, les technologies athermiques se sont développées afin d'obtenir des produits de qualités organoleptiques et nutritionnelles supérieures, mais ne présentant aucun risque pour la santé. La lumière pulsée est une technologie nouvelle qui permet d'inactiver rapidement les microorganismes pathogènes ou qui altèrent les aliments. Elle semble constituer une bonne alternative ou un complément aux processus de décontamination thermiques ou chimiques conventionnels. Cette méthode de préservation des aliments implique l'utilisation de pulses lumineux à large spectre, intenses et brefs. Les effets germicides semblent dus tant aux effets photochimiques que photothermiques. Plusieurs flashs par seconde de lumière pulsée à haute intensité et à large spectre peuvent inactiver des microbes rapidement et efficacement. Cependant, l'efficacité de la lumière pulsée peut être limitée par son faible pouvoir de pénétration de telle sorte que seuls les microorganismes présents à la surface des aliments ou à l'intérieur d'un liquide transparent comme l'eau sont inactivés. Des exemples d'applications alimentaires sont présentés, incluant l'inactivation microbiologique et les effets sur les matrices alimentaires.
\end{abstract}

Mots-clés : lumière pulsée, technologie de décontamination, microorganisme, aliments, revue.

[Traduit par la Rédaction]

\section{Introduction}

Food-borne illness caused by consuming contaminated food remains a major cause of morbidity throughout the world. Clearly, the use of methods to reduce or eliminate food-related microbiological hazards will have a significant impact on the incidence of such diseases. A variety of food preservation methods are available, including heating, dehy-

Received 28 November 2006. Revision received 5 March 2007. Accepted 12 March 2007. Published on the NRC Research Press Web site at cjm.nrc.ca on 1 August 2007.

N. Elmnasser. ${ }^{1}$ Laboratoire d'Analyse, de Traitement et de Valorisation des Polluants de l'Environnement et de Produits. Faculté de Pharmacie de Monastir, rue Avicenne, 5000 Monastir, Tunisie; UMR-INRA 1014 SECALIM ENVN/ENITIAA, Ecole Nationale Vétérinaire de Nantes, Route de Gachet, B.P. 40706-44307, Nantes, CEDEX 03, France.

S. Guillou and M. Federighi. UMR-INRA 1014 SECALIM ENVN/ENITIAA, Ecole Nationale Vétérinaire de Nantes, Route de Gachet, B.P. 40706-44307, Nantes, CEDEX 03, France.

F. Leroi. Département de Sciences et Techniques Alimentaires Marines, Institut Français de Recherche pour l'Exploitation de la Mer, rue de l'Ile d'Yeu, B.P. 21105-44311, Nantes, CEDEX 03, France.

N. Orange. Laboratoire de Microbiologie du Froid, UPRES 2123, Université de Rouen, 55, rue Saint-germain, 27000 Evreux, France. A. Bakhrouf. Laboratoire d'Analyse, de Traitement et de Valorisation des Polluants de l'Environnement et de Produits. Faculté de Pharmacie de Monastir, rue Avicenne, 5000 Monastir, Tunisie.

${ }^{1}$ Corresponding author (e-mail: mnassernoura@yahoo.fr). 
dration, freezing, and the addition of preservatives. Although these technologies can produce safe foods, heating and freezing may contribute to the degradation of certain components, which will impair food quality. To prevent undesirable thermal effects on foods, major efforts have been made to develop nonthermal technologies, which can produce safe but minimally processed foods with satisfactory nutritional and organoleptic qualities (Barbosa-Cánovas et al. 1998). The most promising of these emerging technologies include high-pressure processing, the use of pulsed-electric fields, and the application of pulsed light.

The ability of continuous ultraviolet (UV) light and visible light to inactivate cellular microorganisms is well known (Abad-Lozano and Rodriguez-Velera 1984; Quesnel and Spencer 1985; Kuo et al. 1997; Craik et al. 2001). In recent years, a novel method using high-power electrical energy to generate intense pulses of light has been introduced. It is claimed to exert unique bactericidal effects on food surfaces and in food preparation environments (Mertens and Knorr 1992). After first marketing under the name of Foodco ${ }^{\circledR}$ (Maurice 1994), pulsed-light treatment is being developed by PurePulse Technologies under the trade name PureBright ${ }^{\circledR}$ (Dunn et al. 1995). Today, the literature on pulsed light is rapidly expanding, but a gap remains between basic and applied research with respect to food decontamination (Marquenie et al. 2003a; Gómez-López et al. 2005a; Ozer and Demirci 2005).

This paper describes the application of a pulsed-light process to the prevention of microbial decontamination. The mechanisms that may underlie microbial inactivation achieved are discussed, as are the critical factors influencing this efficiency of the new process. Its efficacy with respect to microbial inactivation (under laboratory conditions or in foods) is investigated.

\section{Principle of the pulsed-light system}

Pulsed light is a nonthermal method for food preservation that involves the use of intense, short duration pulses of a broad spectrum to ensure microbial decontamination on the surface of either foods or packaging materials. The inactivation efficacy of pulsed light depends on the intensity (measured in $\mathrm{J} \cdot \mathrm{cm}^{-2}$ ) and number of pulses delivered. In some studies, the treatment has only been indicated in terms of time (second) and no information is available on the number of pulses applied.

Pulsed light is generated using engineering technologies that magnify power many times to convert high speed electronic pulses into short-duration, high peak energy light pulses. The system comprises 3 main components: the power supply, the pulse configuration device, and the lamp. Energy is stored in a high power capacitor for a relatively long period (a fraction of a second) from which it is released to a specially designed xenon lamp unit within a much shorter time (nanoseconds to milliseconds). High energy delivered to the lamp produces an intense pulse of light focused on the treatment area, which typically lasts a few hundred microseconds. The light produced by the lamp includes broad spectrum wavelengths from UV to near-infrared. The wavelength distribution ranges from 180 to $1100 \mathrm{~nm}$ : UV (180$380 \mathrm{~nm})$, visible light $(380-700 \mathrm{~nm})$, and infrared (700-
$1100 \mathrm{~nm}$ ). During the pulse, this system delivers a spectrum that is 20000 times more intense than sunlight at the earth's surface (Dunn et al. 1995; MacGregor et al. 1998).

The microbiocidal effects of pulsed light have been shown to increase with light intensity (Rowan et al. 1999; Anderson et al. 2000; Wekhof et al. 2001; Sonenshein 2003), although no mathematical dose-response model has yet been validated. The frequency of flashing, the number of lamps, and the flashing configuration depend on treatment application.

\section{Mechanism of action}

The lethal effects of pulsed light can be attributed to its rich broad-spectrum UV content, its short duration, high peak power, and the ability to regulate both the pulse duration and frequency output of flash lamps, which play a major role in microbial destruction (Dunn et al. 1995; Takeshita et al. 2003). Indeed, the UV region is crucial to the efficiency of pulsed-light treatment. It has been confirmed that no killing effect is achieved if a filter is included to remove the UV wavelength region lower than $320 \mathrm{~nm}$ (Takeshita et al. 2002). However, it appears that both the visible and infrared regions, combined with the high peak power of pulsed light, contribute to killing microorganisms.

Various mechanisms have been proposed to explain the lethal effect of pulsed light, all of them related to the UV part of the spectrum and its photochemical and (or) photothermal effect (Anderson et al. 2000; Wekhof 2000; Wekhof et al. 2001; Takeshita et al. 2003; Wuytack et al. 2003).

\section{Photochemical mechanism}

The primary cell target of pulsed light is nucleic acids because DNA is a target molecule for these UV wavelengths (Chang et al. 1985; Bank et al. 1990; Miller et al. 1999). Several mechanisms underlie this inactivation including chemical modifications and DNA cleavage. The germicidal effect of UV light has been attributed primarily to a photochemical transformation of pyrimidine bases in the DNA of bacteria, viruses, and other pathogens to form dimers (Mitchell et al. 1992; Giese and Darby 2000). The formation of such bonds prevents DNA unzipping for replication and the organism becomes incapable of reproduction. Without sufficient repair mechanisms, such damage results in mutations, impaired replication and gene transcription, and ultimately the death of the organism (McDonald et al. 2000; Panico 2005; Wang et al. 2005).

Conventional UV treatment primarily affects DNA through mechanisms that are reversible under certain experimental conditions. Experiments designed to test the enzymatic repair of DNA using pulsed light have shown that this repair does not occur after pulsed-light treatment. The degree of damage caused by pulsed light is supposed to be too severe for repair mechanisms to operate. It is conceivable that the DNA repair system itself is inactivated, as well as other enzymatic functions (Dunn et al. 1995; McDonald et al. 2000; Smith et al. 2002).

UV light is endowed with germicidal properties wthin the wavelength range of 100-280 $\mathrm{nm}$. Several studies have suggested that shorter wavelengths are more efficient against microbes than longer wavelengths, because of their higher 
energy levels (Rowan et al. 1999). Disinfection can almost entirely be attributed to the UV part of the lamp (6-9 log reduction), and UV-C alone is responsible for $50 \%$ of the effect. Moreover, UV-C fluxes alone are sufficient for full inactivation using a flash lamp (Wekhof 2000). Bank et al. (1990) showed that a $6 \log$ reduction in the number of viable bacteria surface inoculated onto trypticase soy agar plates can be achieved using a computer-controlled modulated UV-C light source (100-280 nm). In addition, if $\mathrm{UV}-\mathrm{C}$ is combined with light pulses, a synergistic increase in inactivation of the conidia of Botrytis cinerea and Monilia fructigena fungi is observed (Marquenie et al. 2003b). Wang et al. (2005) showed that the germicidal efficiency of pulsed UV on Escherichia coli is a function of wavelength within the range $230-300 \mathrm{~nm}$, with a maximum effect at $270 \mathrm{~nm}$. No inactivation can be observed above $300 \mathrm{~nm}$.

DNA damage such as the formation of single strand breaks and pyrimidine dimers has been induced in yeast cells after treatment with pulsed light. However, the results clearly demonstrate that DNA damage induced by continuous UV $(254 \mathrm{~nm})$ is slightly greater than that observed with pulsed light, although the killing level of treated yeast cells remains almost the same in both cases (Takeshita et al. 2003). It is likely that the killing effect of pulsed light is not wholly dependent on DNA damage.

\section{Photothermal mechanism}

The lethal action of pulsed light also can be due to a photothermal effect. Wekhof (2000) proposed that with an energy exceeding $0.5 \mathrm{~J} \cdot \mathrm{cm}^{-2}$ the disinfection is achieved through bacterial disruption during their temporary overheating resulting from the absorption of all UV light from a flash lamp. This overheating can be attributed to a difference in UV light absorption by bacteria and that of a surrounding medium. The water content of bacteria is vaporized, generating a small steam flow that induces membrane disruption (Takeshita et al. 2003). Moreover, Wekhof et al. (2001) showed a ruptured top of treated Aspergillus niger spores evidently punctured by an escape of overheated contents of the spore, which became empty after such an internal "explosion" resulted in an "evacuation" of its contents during the light pulse. According to Mertens and Knorr (1992), in the case of UV-rich treatment the biocidal action is attributable to a combined photothermal and photochemical effect. The action is primarily photothermal in the absence of UV wavelengths, the light pulses being simply a fast method of transferring large amounts of thermal energy to the surface of the product (Mertens and Knorr 1992).

It has been shown that the sample temperature increases significantly after exposure to pulsed light at levels enabling sterility. Because proteins retain their function after exposure to low doses that completely inactivate nucleic acids, it is unlikely that cell death is caused by a heat mechanism at these doses. Furthermore, because proteins are heat sensitive, it is reasonable to suppose that heat might play a role in cell death at high doses resulting in a loss of protein function (Cover et al. 2001).

\section{Physical mechanism (effect on membrane and cell composition)}

The impact of pulsed light on proteins, membranes, and other cellular materials is probably concomitant with the destruction of, most likely, nucleic acids. Takeshita et al. (2003) compared the inactivation of Saccharomyces cerevisiae cells by pulsed light and classical continuous UV. They found that the concentration of eluted protein from yeast cells after pulsed-light treatment was higher than observed under continuous UV treatment. This could indicate potential cell membrane damage induced by the pulsed-light treatment. Transmission electron micrographs of yeast cells after irradiation with pulsed light has revealed distinct structural change in the yeast cells. These include expanded vacuoles, cell membrane distortion, and change to circular shape, strongly suggesting that cell membrane damage can be induced by pulsed-light treatment. On the other hand, after treatment with continuous UV light, the yeast cell structure was almost the same as in the case of nontreated cells (Takeshita et al. 2003). Electron micrographs of treated A. niger spores revealed that the top of the spore was ruptured. The collapsed and deformed spores exhibited deep craters during the light pulse (Wekhof et al. 2001). Moreover, microscopic analysis after high-energy UV-pulsedlight treatment revealed that most Bacillus subtilis spores had disintegrated or become deformed (Wekhof et al. 2001; Sonenshein 2003).

\section{Limitations to the pulsed-light system}

The efficiency of pulsed light depends on microbial exposure. For example, the sterilization of packaged products is possible if the packaging is UV transparent. As noted above, because foods are generally opaque and have irregular surfaces, less microbial destruction is achieved. Generally, in nontransparent media pulsed light can only be used as a surface treatment for the first $2 \mu \mathrm{m}$ (Wallen et al. 2001). Limited pulsed-light efficiency because of a greater shadow effect has been observed in food products. Indeed, microorganisms may penetrate via crevices or irregularities present on the food surface, or through the epidermis of a vegetable (Marquenie et al. 2003a; Gómez-López et al. 2005a; Lagunas-Solar et al. 2006; Ozer and Demirci 2006). Owing to the shadowing effect of pulsed UV photon sources, fungal populations on the surface of fruits require treatment at higher energy levels than those present on a solid culture medium 2- to 6-fold (Lagunas-Solar et al. 2006). These results suggest that it may be possible to add devices to the pulsed-light system to create multidirectional pulsed light or generate the random movement (rotation and (or) throughput operations) of products so that all surfaces are exposed uniformly and any protected microorganisms can be attained.

Food composition also affects the efficacy of the decontamination by pulsed light. High-protein or oily foods are not suitable for decontamination by intense light pulses. It is possible that part of the radiation is absorbed by proteins and oils, reducing the effective radiation dose available for microbial inactivation. The carbohydrate and water content in foods has variable effects on the efficiency of microbial destruction by pulsed light, depending on the type of microorganism (Gómez-López et al. 2005a). Roberts and Hope (2003) found that the presence of proteins substantially inhibits viral inactivation. Indeed, in phosphate-buffered saline 
alone, a dose of $1 \mathrm{~J} \cdot \mathrm{cm}^{-2}$ can be sufficient to inactivate $6 \log$ of all viruses tested. However, in fetal-calf serum $(0.2 \% \mathrm{~m} / \mathrm{v}$ protein), viral inactivation is less effective, a dose of $2 \mathrm{~J} \cdot \mathrm{cm}^{-2}$ being necessary to achieve effective inactivation of $5 \log$ of most of the viruses tested.

Gómez-López et al. (2005b) showed that the efficiency of inactivation is markedly reduced with the increase in counts of Listeria monocytogenes on the surface of an agar medium. Similar conclusions regarding reduced efficacy on a huge bacterial population in a contaminated sample were reached by Wuytack et al. (2003), who postulated that heavily contaminated products might be less efficiently decontaminated because of the shadow effect. In the case of liquid products, the same shading effect can be expected in high cell populations (Ghasemi et al. 2003). The optimum efficacy pulsed light was achieved when food products were flashed as soon as possible after processing, before any increase in the numbers of endogenous microflora.

The pulsed-light system is deemed to be part of a nonthermal technologies by food scientists, designed to ensure stable and safe food products without the damage caused by heating. This has been identified as a problem during most studies. For example, the maximum treatment time used by Jun et al. (2003) was limited to $100 \mathrm{~s}$ to inactivate fungal spores of A. niger in corn meal because the sample temperature rose beyond $120{ }^{\circ} \mathrm{C}$, which could lead to a change in food properties and thus impair quality. Fine and Gervais (2004) failed to achieve a 1 log reduction of Saccharomyces cerevisiae in wheat flour and black pepper because the treatment caused both products to burn. Calorimetry results indicated a rapid modification of product colour well before the decontamination threshold was reached and was clearly more rapid for black pepper than wheat flour (Fine and Gervais 2004). This color modification can be attributed to overheating combined with oxidation. Krishnamurthy et al. (2004) reported a temperature increase of around $20{ }^{\circ} \mathrm{C}$ after the flashing of phosphate buffer and Baird-Parker agar for $20 \mathrm{~s}$. Gómez-López et al. (2005a, 2005b) reported problems with overcoming sample heating during their experiments, which restricted the duration of the procedure and distance between the sample and the lamp.

The results of all these studies show that temperature increases with longer treatment times. However, there is no significant temperature increase during the first few seconds of treatment, and inactivation is hypothesized to occur primarily because of pulsed UV light and not because of any synergistic effect from this temperature increase. These studies demonstrate that treatment for long periods is impossible without seriously impairing quality, unless an efficient cooling system can be incorporated in the equipment.

Pulsed UV-light treatment can therefore be considered to as a nonthermal process, but only if applied for short durations. The following key recommendations have been made in an attempt to minimize treatment temperature during testing procedures.

- A high pulse peak power reduces the need for high average power.

- Lamps must be turned on or off immediately during sterilization.

- Short-duration pulses must be applied.
- A cooling period must be allowed between pulses.

- A low infrared spectrum content must be ensured (Panico 2005).

\section{Inactivation of microorganisms with pulsed- light treatment}

A large number of publications and presentations at scientific meetings have documented the ability of pulsed light to destroy microorganisms. The differences between the materials used and experimental conditions under which different studies were performed have given rise to variable results, which render any comparisons difficult. Nevertheless, Tables 1,2, and 3 summarize the main results obtained during different studies of microbial inactivation (bacteria, fungi, yeasts, and viruses) with pulsed light in vitro in foods and water.

\section{Microbial inactivation during laboratory conditions}

\section{Inactivation of bacteria}

From the results described by Gómez-López et al. $(2005 b)$, it is clear that high decontamination effects (from $1.2 \log$ to more than $5.9 \mathrm{log}$ ) of intense pulsed light with a pulse duration of $30 \mu$ s and pulse intensity of $7 \mathrm{~J}$ can be observed after 50 pulses on different microorganisms inoculated on agar media (Table 1).

Ghasemi et al. (2003) chose E. coli and Salmonella enteritidis to study the inactivation effects of pulsed light, applying 5-100 pulses with a spectral range of $200-530 \mathrm{~nm}$ to bacterial suspensions transferred into empty standard Petri dishes. Analysis of the illuminated samples indicated that both E. coli and Salmonella enteritidis showed a $9 \log$ order reduction after treatment with 100 pulses of 9 J. For E. coli, 100 pulses of $4.5 \mathrm{~J}$ for each pulse produced a $7 \log$ order reduction, when only an approximate $0.5 \log$ order reduction was observed after 5 pulses of 4.5 and $9 \mathrm{~J}$. These results demonstrate that the mechanism underlying the pulsed-light process is attributable to the action of high energy per pulse. The relatively low rate of cell reduction during the first few pulses is probably because of the initial very high cell population $\left(1.3 \times 10^{9} \mathrm{CFU} \cdot \mathrm{mL}^{-1}\right)$ causing a fall-off in UV intensity through the $3.28 \mathrm{~mm}$ depth of the sample.

Rowan et al. (1999) reported a 6 log reduction in Listeria monocytogenes, E. coli O157:H7, Salmonella enteritidis, Pseudomonas aeruginosa, Bacillus cereus, and Staphylococcus aureus inoculated on agar plates using 200 pulses of high-UV light (pulse duration, $100 \mathrm{~ns}$ ), whereas only a 12 log-order reduction was achieved with low-UV light. A pulsed-light source of lower UV intensity was shown to be significantly less effective than higher UV intensity in reducing microbial populations. So, the UV part of the spectrum is the most important for microbial inactivation.

The results obtained by MacGregor et al. (1998) show that as few as 64 light pulses (spectral range of 200$530 \mathrm{~nm}$ ) of $1 \mu \mathrm{s}$ duration and $3 \mathrm{~J}$ intensity are required to reduce E. coli $\mathrm{O} 157: \mathrm{H} 7$ and L. monocytogenes populations spread on agar surfaces by 4 and 2 logs, respectively. This level of reduction is increased to 7 and $6 \log$ orders, respectively, with 512 pulses. Krishnamurthy et al. (2004) also observed a 7-8 log reduction of Staphylococcus aureus in 
Table 1. Summary of published data for the microbial inactivation in vitro with the pulsed-light system.

\begin{tabular}{|c|c|c|c|c|c|c|}
\hline Microorganism & $\begin{array}{l}\text { Treatment } \\
\text { media }\end{array}$ & Energy & $\begin{array}{l}\text { No. of } \\
\text { pulses }\end{array}$ & $\begin{array}{l}\text { Initial } \\
\text { population } \\
(\log )\end{array}$ & $\begin{array}{l}\text { Reduction in } \\
\text { population } \\
(\log )\end{array}$ & Reference \\
\hline \multicolumn{7}{|l|}{ Vegetative cells } \\
\hline Pseudomonas aeruginosa & Agar & $3 \mathrm{~J}$ & 200 & 8.7 & 6.8 & Rowan et al. 1999 \\
\hline Pseudomonas fluorescens & Agar & $7 \mathrm{~J}$ & 50 & 5.6 & 4.2 & Gómez-López et al. $2005 b$ \\
\hline Escherichia coli & Agar & $7 \mathrm{~J}$ & 50 & 5.3 & 4.7 & Gómez-López et al. $2005 b$ \\
\hline Escherichia coli & Agar & $3 \mathrm{~J}$ & 512 & 8.3 & 6.82 & MacGregor et al. 1998 \\
\hline Escherichia coli & Agar & $3 \mathrm{~J}$ & 200 & 9.6 & 6.2 & Rowan et al. 1999 \\
\hline Klebsiella oxytoca & Agar & $7 \mathrm{~J}$ & 50 & 5.1 & 4.2 & Gómez-López et al. $2005 b$ \\
\hline $\begin{array}{r}\text { Photobacterium } \\
\text { phosphoreum }\end{array}$ & Agar & $7 \mathrm{~J}$ & 50 & 4.8 & $>4.4$ & Gómez-López et al. $2005 b$ \\
\hline Listeria monocytogenes & Agar & $7 \mathrm{~J}$ & 50 & 5 & 2.8 & Gómez-López et al. $2005 b$ \\
\hline Listeria monocytogenes & Agar & $3 \mathrm{~J}$ & 200 & 9.4 & 4.4 & Rowan et al. 1999 \\
\hline Listeria monocytogenes & Agar & $3 \mathrm{~J}$ & 512 & 8.38 & 6.25 & MacGregor et al. 1998 \\
\hline \multicolumn{7}{|l|}{ Spores } \\
\hline Bacillus cereus & Agar & $7 \mathrm{~J}$ & 50 & 6.3 & $>5.9$ & Gómez-López et al. $2005 b$ \\
\hline Bacillus circulans & Agar & $7 \mathrm{~J}$ & 50 & 5.7 & 3.7 & Gómez-López et al. $2005 b$ \\
\hline \multicolumn{7}{|l|}{ Fungi } \\
\hline Botrytis cinerea & Agar & $7 \mathrm{~J}$ & 1500 & 6 & 3 & Marquenie et al. $2003 a$ \\
\hline Monilia fructigena & Agar & $7 \mathrm{~J}$ & 1500 & 6 & 4 & Marquenie et al. $2003 a$ \\
\hline Aspergillus niger & Saline solution & $1 \mathrm{~J} \cdot \mathrm{cm}^{-2}$ & 5 & 6 & 4.8 & Wekhof et al. 2001 \\
\hline \multicolumn{7}{|l|}{ Yeasts } \\
\hline
\end{tabular}

cultures of suspended and agar-seeded cells treated for $5 \mathrm{~s}$ or longer by pulsed UV light at $5.6 \mathrm{~J} \cdot \mathrm{cm}^{-2}$ and a pulse duration of $360 \mu \mathrm{s}$. The recent study by Feuilloley et al. (2006) has shown that a single light pulse at a dose of $1 \mathrm{~J} \cdot \mathrm{cm}^{-2}$ is sufficient to entirely reduce a bacterial population of $P$. aeruginosa $\left(10^{6} \mathrm{CFU} \cdot \mathrm{mL}^{-1}\right)$ suspended in ampoules of solution for injection.

It has also been demonstrated that 20 pulses with $1 \mathrm{~J} \cdot \mathrm{cm}^{-2}$ of $0.3 \mathrm{~s}$ duration achieves more than a $6 \mathrm{log}$ reduction of Bacillus pumilus spores in aqueous suspensions in a polyethylene container (Dunn et al. 1997). Bushnell et al. (1998) found that spores of Bacillus subtilis, Bacillus pumilus, and Bacillus stearothermophilus are completely inactivated (6-8 log reductions) by up to 3 pulses. Moreover, Gómez-López et al. (2005b) reported a 3.7 and >5.9 log reduction in Bacillus circulans and Bacillus cereus, respectively, when microorganisms were treated on agar surface with 50 pulses with each pulse providing $7 \mathrm{~J}$.

\section{Inactivation of fungi}

Fungal counts (A. niger and Fusarium culmorum) can be reduced $4.5 \log$ after 1000 light pulses of UV light within a wavelength range of 200-300 $\mathrm{nm}$ (Anderson et al. 2000). These results agree with those obtained for both conidia $\mathrm{Bo}$ trytis cinerea and Monilia fructigena (Marquenie et al. $2003 b$ ) subjected to light pulse treatments of increasing duration. There was no difference in reaction between the 2 fungi and the inactivation was typically sigmoid. For treatment durations shorter than $40 \mathrm{~s}$ (equivalent to 600 pulses), little or no inactivation could be observed. Conidia inactivation increased by approximately $2 \log$ units between 40 and $100 \mathrm{~s}$ (equivalent to 600 and 1500 pulses, respectively). Maximal reduction of Botrytis cinerea and $M$. fructigena, reaching 3 and $4 \log$ units, respectively, was achieved with light pulse treatment for up to $250 \mathrm{~s}$, but no total inactivation could be obtained (Marquenie et al. 2003b). However, other studies have demonstrated a 6-8 log reduction in A. niger spores with a maximum of only 6 light pulses (Bushnell et al. 1998; Wekhof et al. 2001).

\section{Inactivation of yeasts and viruses}

Rowan et al. (1999) reported a 5 log reduction in Saccha- 
Table 2. Summary of published data for the microbial inactivation in food with the pulsed-light system.

\begin{tabular}{|c|c|c|c|c|c|c|c|}
\hline Food & Microorganism & $\begin{array}{l}\text { Microbial } \\
\text { contamination }\end{array}$ & Energy & $\begin{array}{l}\text { No. of } \\
\text { pulses }\end{array}$ & $\begin{array}{l}\text { Initial } \\
\text { population } \\
(\log )\end{array}$ & $\begin{array}{l}\text { Reduction } \\
\text { in population } \\
\text { (log) }\end{array}$ & Reference \\
\hline White cabbage & Aerobic mesophiles & Natural & $7 \mathrm{~J}$ & 675 & 3.64 & 0.64 & $\begin{array}{l}\text { Gómez-López et } \\
\text { al. } 2005 a\end{array}$ \\
\hline Iceberg lettuce & Aerobic mesophiles & Natural & $7 \mathrm{~J}$ & 675 & 6.5 & 1.24 & $\begin{array}{l}\text { Gómez-López et } \\
\text { al. } 2005 a\end{array}$ \\
\hline Bulk tank milk & Aerobic mesophiles & Natural & $25 \mathrm{~J} \cdot \mathrm{cm}^{-2}$ & 110 & 3 & $>2$ & Smith et al. 2002 \\
\hline Wheat flour & $\begin{array}{l}\text { Saccharomyces } \\
\text { cerevisiae }\end{array}$ & Inoculation & $1.95 \mathrm{~J} \cdot \mathrm{cm}^{-2}$ & 64 & 9 & 0.7 & $\begin{array}{l}\text { Fine and Gervais } \\
2004\end{array}$ \\
\hline Black pepper & $\begin{array}{l}\text { Saccharomyces } \\
\text { cerevisiae }\end{array}$ & Inoculation & $1.95 \mathrm{~J} \cdot \mathrm{cm}^{-2}$ & 64 & 9 & 2.93 & $\begin{array}{l}\text { Fine and Gervais } \\
2004\end{array}$ \\
\hline Corn meal & Aspergillus niger & Inoculation & $5.6 \mathrm{~J} \cdot \mathrm{cm}^{-2}$ & 300 & 5 & $1.35-4.95$ & Jun et al. 2003 \\
\hline Salmon fillets & $\begin{array}{l}\text { Listeria } \\
\quad \text { monocytogenes }\end{array}$ & Inoculation & $5.6 \mathrm{~J} \cdot \mathrm{cm}^{-2}$ & 135 & 8.7 & $0.72-0.8$ & $\begin{array}{l}\text { Ozer and Demirci } \\
2005\end{array}$ \\
\hline Salmon fillets & Escherichia coli & Inoculation & $5.6 \mathrm{~J} \cdot \mathrm{cm}^{-2}$ & 135 & 8.7 & $0.24-0.91$ & $\begin{array}{l}\text { Ozer and Demirci } \\
2005\end{array}$ \\
\hline
\end{tabular}

Table 3. Summary of published data for the microbial inactivation in water with the pulsed-light system.

\begin{tabular}{llcllll}
\hline & $\begin{array}{l}\text { Microbial } \\
\text { contamination }\end{array}$ & $\begin{array}{l}\text { Energy } \\
\left(\mathrm{J} \cdot \mathrm{cm}^{-2}\right)\end{array}$ & $\begin{array}{l}\text { No. of } \\
\text { pulses }\end{array}$ & $\begin{array}{l}\text { Initial } \\
\text { population } \\
(\log )\end{array}$ & $\begin{array}{l}\text { Reduction in } \\
\text { population } \\
(\log )\end{array}$ & Reference \\
\hline Klebsiella terrigena & Inoculation & 0.25 & 2 & 5.5 & $>7$ & Huffman et al. 2000 \\
Bacillus subtilis & Inoculation & 15.8 & 3 & 9 & $>6$ & Sonenshein 2003 \\
Rotavirus SA11 & Inoculation & 0.25 & 2 & 5 & $>4$ & Huffman et al. 2000 \\
Poliovirus type 1 & Inoculation & 0.25 & 2 & 4.5 & $>4$ & Huffman et al. 2000 \\
Cryptosporidium parvum & Inoculation & 0.25 & 2 & 4.25 & $>4$ & Huffman et al. 2000 \\
\hline
\end{tabular}

romyces cerevisiae seeded on agar plates using 200 high-UV light pulses, while after 5 flashes of pulsed-light treatment at $0.7 \mathrm{~J} \cdot \mathrm{cm}^{-2}$, Saccharomyces cerevisiae cells suspended in a potassium phosphate buffer were reduced by 6 log (Takeshita et al. 2003). Likewise, Fine and Gervais (2004) documented a $7 \log$ reduction of $S$. cerevisiae dried on glass beads and quartz plate after treatment with 24 pulses at $58 \mathrm{~J} \cdot \mathrm{cm}^{-2}$. The yeasts Candida lambica and Rhodotorula mucilaginosa were reported to be reduced by 3 log on agar media after pulsed-light treatment (Gómez-López et al. 2005b).

The inactivation of enveloped and nonenveloped viruses by treatment with high intensity broad spectrum pulsed light was investigated by Roberts and Hope (2003). In phosphate buffered saline, a total dose of $1 \mathrm{~J} \cdot \mathrm{cm}^{-2}$ is sufficient to effectively inactivate $4.8-7.2 \log$ of viruses.

The results of in vitro experiments have demonstrated that fungi are more resistant to pulsed light than bacteria (Rowan et al. 1999; Anderson et al. 2000). Pulsed-light treatment is more effective on solid surfaces than in liquids (Marquenie et al. 2003b; Krishnamurthy et al. 2004).
No clear rules can be established regarding the sensitivity of the different investigated groups of microorganisms (Gómez-López et al. 2005b). Rowan et al. (1999) reported that Gram-positive bacteria are more resistant than Gramnegative organisms, although the pattern they presented was not particularly clear; the same trend was reported by MacGregor et al. (1998) and Anderson et al. (2000), but only with different species.

To evaluate the possibility of the development of resistance to pulsed light, microorganisms surviving after light pulse treatment were subcultured and subjected again to light treatment. No differences in inactivation by light pulses were observed when compared with initial microorganisms, which suggests that no resistance develops as a result of pulsed-light treatment (Marquenie et al. 2003b; GómezLópez et al. 2005b).

\section{Microbial inactivation in foods}

\section{Foods of vegetable origin}

The decontamination effect of pulsed light on several 
minimally processed vegetables has been studied. Log reductions between 0.56 and 2.04 can be achieved with mesophilic, aerobic microorganisms after treating spinach, celeriac, radicchio, iceberg lettuce, white cabbage, carrots, green bell pepper, and soybean sprouts with 2700 pulses per side at both sides (Gómez-López et al. 2005a). The differences in log reduction between samples may be related to differences in resistance of the natural microbial populations affecting each vegetable, the site of microorganisms on and in the samples (shadow effects), and (or) protective substances in specific vegetables.

Regarding fruits, Marquenie et al. (2003a) found no inhibition of fungal development following the treatment of Botrytis cinerea inoculated on strawberries for up to $250 \mathrm{~s}$, and observed no effect on berry firmness. A combination of thermal treatment with light pulses did not produce a significant difference in terms of fungal survival. Combining pulsed-light treatment with UV-C illumination did not significantly reduce fungal development on inoculated fruit. Moreover, resistance against fungal infections in treated fruit was not induced after pulsed-light treatment (Marquenie et al. 2003a).

\section{Food powders and seeds}

With respect to the decontamination of food powders, wheat flour and black pepper have been studied. At an energy level of $31.12 \mathrm{~J} \cdot \mathrm{cm}^{-2}$ (64 pulses), Fine and Gervais (2004) reached 0.7 and $2.93 \quad \log$ reductions in Saccharomyces cerevisiae cells inoculated in wheat flour and black pepper, respectively. The difference in decimal reduction between wheat flour and black pepper can be explained by the difference in initial color. Jun et al. (2003) studied the inactivation of $A$. niger spores on corn meal, reporting a reduction of $4.93 \log$ after $100 \mathrm{~s}$ pulsed UV-light treatment at an energy dose of $5.6 \mathrm{~J} \cdot \mathrm{cm}^{-2}$ at $3 \mathrm{~cm}$ from the strobe, but only a $2.95 \log$ reduction at $13 \mathrm{~cm}$ using the same treatment.

Similarly, when modelling the inactivation of $E$. coli O157:H7 in alfafa seeds, Sharma and Demirci (2003) reported $4.89 \log$ reduction at distance of a $8 \mathrm{~cm}$, but a reduction of only $1.42 \log$ at $13 \mathrm{~cm}$ when the seeds were subjected to UV pulses for $75 \mathrm{~s}$. These authors found that inactivation diminished when the seed layer was thicker. In addition, pulsed light did not significantly affect the percentage germination of alfalfa seeds; that of untreated seeds was $86 \%$, while ranging from $34.1 \%$ to $89.2 \%$ for treated seeds.

\section{Dairy products}

The microbial population in curds of commercial dry cottage cheese inoculated with Pseudomonas spp. and treated with pulsed light with an energy of $16 \mathrm{~J} \cdot \mathrm{cm}^{-2}$ and a pulse duration of $0.5 \mathrm{~ms}$ can be reduced by $1.5 \log$ after 2 pulses (Dunn et al. 1991).

The decontamination of bulk tank milk with pulsed UV light (248 nm) was investigated by Smith et al. (2002). One millilitre of bulk tank milk samples, in quartz cuvettes, was exposed to pulsed UV light at $25 \mathrm{~J} \cdot \mathrm{cm}^{-2}$. The pulsed UV light exposure resulted in total reduction of mesophilic aerobes. Moreover, the inactivation of 7 different potential foodborne bacterial pathogens (E. coli O157:H7, L. monocytogenes, Salmonella choleraesuis, Yersinia enterocolitica,
Staphylococcus aureus, Aeromonas hydrophila, and Serratia marcescens) by pulsed UV light was studied in the same conditions for the treatment of mesophilic aerobes. No growth of any plated or subcultured samples was observed, even after incubation for 21 days (Smith et al. 2002).

\section{Other foods}

Honey inoculated with Clostridium sporogenes spores was treated with pulsed light at $5.6 \mathrm{~J} \cdot \mathrm{cm}^{-2}$ per pulse. The number of pulses, the distance between the honey and the lamp, and the depth of the honey were investigated (Hillegas and Demirci 2003). Increasing the number of pulses (or prolonging the treatment time) appeared to be effective in inactivating spores. Reducing the distance between the honey surface and the UV lamp also enabled improved spore reduction. When the depth of the honey was decreased the spore inactivation increased. Even though varying these 3 parameters enabled the improved inactivation of Clostridium sporogenes, it failed to inactivate the spores completely. It appears that UV light has limited penetration into honey.

The ability of pulsed light $\left(5.6 \mathrm{~J} \cdot \mathrm{cm}^{-2}\right)$ to inactivate E. coli $\mathrm{O} 157: \mathrm{H} 7$ and L. monocytogenes Scott A on raw salmon fillets was investigated by Ozer and Demirci (2005) in a comparative study (muscle versus skin). For $E$. coli O157:H7, the maximum reduction was $1.09 \log$ on muscle at a distance of $8 \mathrm{~cm}$ for a $60 \mathrm{~s}$ treatment, whereas an $0.86 \mathrm{log}$ reduction was achieved on skin at $5 \mathrm{~cm}$ with a $30 \mathrm{~s}$ treatment. For L. monocytogenes Scott A, the maximum reduction was $1.02 \log$ at $8 \mathrm{~cm}$ with a $60 \mathrm{~s}$ treatment on skin, and a $0.74 \log$ reduction on muscle at $8 \mathrm{~cm}$ with a $60 \mathrm{~s}$ treatment.

\section{Microbial inactivation in water}

Regarding liquid samples, Huffman et al. (2000) investigated the inactivation of bacteria (Klebsiella terrigena), viruses (poliovirus and rotavirus), and parasites (Cryptosporidium parvum) inoculated in water with pulsed light at $250 \mathrm{~mJ} \cdot \mathrm{cm}^{-2}$. Two pulses achieved a more than $7 \mathrm{log}$ reduction of a $K$. terrigena population. A more than $4 \log$ reduction was obtained for virus and parasite populations. Sonenshein (2003) investigated the inactivating effect of high-intensity pulsed UV light with an energy level of $15.8 \mathrm{~J} \cdot \mathrm{cm}^{-2}$ on Bacillus subtilis spores suspended in sterile, deionized water, where 3 pulses produced more than a $6 \log$ reduction.

Increasing numbers of studies are targeting the effects of pulsed light on microorganisms in foods or under laboratory conditions. It has been shown that reductions in microbial populations increase with the decreasing distance from the sample, with an increase in the number of pulses (or a longer treatment time), and with a reduction in the depth (or thickness) of the product. Because foods are generally opaque and may be irregular, wet, or dry, lower decontamination levels have been achieved than during in vitro assays (Dunn et al. 1995). In addition, because the pulsed-light decontamination effect seems to depend on light absorption by microorganisms, some food components may also absorb effective wavelengths and thus hamper the efficacy of this treatment (Roberts and Hope 2003; Gómez-López et al. 2005a). 


\section{Conclusion}

The pulsed-light process is a promising alternative for microbial inactivation. All published results have demonstrated a high degree of inactivation efficiency. In terms of the sterilization dose, pulsed light may represent the most energy-efficient mechanism to date. However, pulse generation requires a considerable amount of energy and an external cooling system is necessary for some units. The available data suggests that bacterial inactivation during irradiation with a flash lamp is due to both a UVC germicidal action and to bacterial disruption as a result of temporary overheating by the flash lamp spectrum. However, the mechanisms underlying the destruction of microorganisms by wavelengths of light requires further study and elucidation. In laboratory conditions, the potential of pulsed light on agar has been clearly demonstrated. However, the reduction in bacteria on real foods is low. Although the peak power of pulses is very high because of their short duration, it appears that pulsed light does not penetrate very deeply into food products. Therefore, further research is needed to evaluate its applicability for the decontamination of various food products that are most commonly associated with food poisoning.

\section{References}

Abad-Lozano, J.L., and Rodriguez-Velera, F. 1984. Photodynamic inactivation of Bacillus subtilis spores. J. Appl. Bacteriol. 57: 339-343.

Anderson, J.G., Rowan, N.J., MacGregor, S.J., Fouracre, R.A., and Farish, O. 2000. Inactivation of food-borne enteropathogenic bacteria and spoilage fungi using pulsed-light. IEEE Trans. Plasma. Sci. 28: 83-88.

Bank, H.L., John, J., Schmehl, M.K., and Dratch, R.J. 1990. Bactericidal effectiveness of modulated UV light. Appl. Environ. Microbiol. 56: 3888-3889. PMID:2128016.

Barbosa-Cánovas, G.V., Gongora-Nieto, M.M., and Swanson, B.G. 1998. Nonthermal electrical methods in food preservation. Food Sci. Int. 4: 363-370.

Bushnell, A., Cooper, J.R., Dunn, J., Leo, F., and May, R. 1998. Pulsed light sterilization tunnels and sterile-pass-throughs. Pharm. Eng. 18: 48-58.

Chang, J.C., Ossoff, S.F., Lobe, D.C., Dorfman, M.H., Dumais, C.M., Qualls, R.G., and Johnson, J.D. 1985. UV inactivation of pathogenic and indicator microorganisms. Appl. Environ. Microbiol. 49: 1361-1365. PMID:2990336.

Cover, W.H., Holloway, J.M., Xue, H., and Busby, T.F. 2001. Inactivation of lipid enveloped and non-enveloped viruses in human plasma proteins with broad spectrum pulsed light. Plasma Product Biotechnology Meeting, Downstream May 2001. pp. 42-45. [Abstr.]

Craik, S.A., Weldon, D., Finich, G.R., Bolton, J.R., and Belosevic, M. 2001. Inactivation of Cryptosporidium parvum oocysts using medium- and low-pressure ultraviolet radiation. Water Res. 35: 1387-1398. doi:10.1016/S0043-1354(00)00399-7. PMID:11317885.

Dunn, J., Clark, R.W., Asmus, J.F., Pearlman, J.S., Boyer, K., Pairchaud, F., and Hofmann, G. 1991. Methods for preservation of foodstuffs. US Patent and Trademark Office, Alexandria, Va., USA. US patent 5034235.

Dunn, J., Ott, T., and Clark, W. 1995. Pulsed-light treatment of food and packaging. Food Technol. 49: 95-98.

Dunn, J., Burgess, D., and Leo, F. 1997. Investigation of pulsed light for terminal sterilization of WFI filled blow/fill/seal poly- ethylene containers. PDA J. Pharm. Sci. Technol. 51: 111-115. PMID:9203823.

Feuilloley, M.G.J., Bourdet, G., and Orange, N. 2006. Effect of white pulsed light on Pseudomonas aeruginosa culturability and its endotoxin when present in ampoules for injection. Eur. J. Parenteral Pharm. Sci. 11: 37-43.

Fine, F., and Gervais, P. 2004. Efficiency of pulsed UV light for microbial decontamination of food powders. J. Food Prot. 67: 787-792. PMID:15083732.

Ghasemi, Z., Macgregor, S., Anderson, J., and Lamont, Y. 2003. Development of an integrated solid-state generator for light inactivation of food-related pathogenic bacteria. Meas. Sci. Technol. 14: 26-32. doi:10.1088/0957-0233/14/6/402.

Giese, N., and Darby, J. 2000. Sensitivity of microorganisms to different wavelengths of UV light: implications on modelling of medium pressure UV systems. Water Res. 34: 4007-4013. doi:10.1016/S0043-1354(00)00172-X.

Gómez-López, V.M., Devlieghere, F., Bonduelle, V., and Debevere, J. 2005a. Intense light pulses decontamination of minimally processed vegetables and their shelf-life. Int. J. Food Microbiol. 103: 79-89. PMID:16084268.

Gómez-López, V.M., Devlieghere, F., Bonduelle, V., and Debevere, J. 2005b. Factors affecting the inactivation of microorganisms by intense light pulses. J. Appl. Microbiol. 99: 460-470. doi:10.1111/j.1365-2672.2005.02641.x. PMID:16108787.

Hillegas, S.L., and Demirci, A. 2003. Inactivation of Clostridium sporogenes in clover honey by pulsed UV-light treatment. In Agriculture Engineering International: the CIGR Journal of Sientific Research and Development. Vol. V. Manuscript FP 03009.

Huffman, D.E., Slifko, T.R., Salisbury, K., and Rose, J.B. 2000. Inactivation of bacteria, virus, and Cryptosporidium by a point-ofuse device using pulsed broad spectrum white light. Water Res. 34: 2491-2498. doi:10.1016/S0043-1354(00)00014-2.

Jun, S., Irudayaraj, J., Demirci, A., and Geiser, D. 2003. Pulsed UV-light treatment of corn meal for inactivation of Aspergillus niger spores. Int. J. Food Sci. Technol. 38: 883-888.

Krishnamurthy, K., Demirci, A., and Irudayaraj, J. 2004. Inactivation of Staphylococcus aureus by pulsed UV-light sterilization. J. Food Prot. 67: 1027-1030. PMID:15151245.

Kuo, F.L., Carey, J.B., and Ricke, S.C. 1997. UV irradiation of shell eggs: effect of population of aeroes, moulds and inoculated Salmonella typhimurium. J. Food Prot. 60: 639-643.

Lagunas-Solar, M.C., Piňa, C., MacDonal, J.D., and Bolkan, L. 2006. Development of pulsed UV light processes for surface fungal disinfection of fresh fruits. J. Food Prot. 69: 376-384. PMID:16496579.

MacGregor, S.J., Rowan, N.J., Mcllvaney, L., Anderson, J.G., Fouracre, R.A., and Farish, O. 1998. Light inactivation of foodrelated pathogenic bacteria using a pulsed power source. Lett. Appl. Microbiol. 27: 67-70. doi:10.1046/j.1472-765X.1998. 00399.x. PMID:9750325.

Marquenie, D., Michiels, C.W., Van Impe, J.F., Schrevens, E., and Nicola, B.N. 2003a. Pulsed white light in combinations with UV$\mathrm{C}$ and heat to reduce storage rot of strawberry. Postharvest Biol. Technol. 28: 455-461. doi:10.1016/S0925-5214(02)00214-4.

Marquenie, D., Geeraed, A.H., Lammertyn, J., Soontjens, C., Van Impe, J.F., Michiels, C.W., and Nicolaï, B.M. 2003b. Combinations of pulsed white light and UV-C or mild heat treatment to inactivate conidia of Botrytis cinerea and Monilia fructigena. Int. J. Food Microbiol. 85: 185-196. doi:10.1016/S01681605(02)00538-X. PMID:12810282.

Maurice, J. 1994. The rise and rise of food poisoning. New Sci. 144: 28-33.

McDonald, K.F., Curry, R.D., Clevenger, T.E., Unklesbay, K., Ei- 
senstark, A., Golden, J., and Morgen, R.D. 2000. A comparison of pulsed and continuous ultraviolet light sources for the decontamination of surfaces. IEEE Trans. Plasma Sci. 28: 1581-1587. doi:10.1109/27.901237.

Mertens, B., and Knorr, D. 1992. Developments of nonthermal processes for food preservation. Food Technol. 46: 124-133.

Miller, R., Jeffrey, W., Mitchell, D., and Elasri, M. 1999. Bacterial responses to ultraviolet light. ASM News, 65: 535-541.

Mitchell, D.L., Jen, J., and Cleaver, J.E. 1992. Sequence specificity of cyclobutane pyrimidine dimers in DNA treated solar (ultraviolet B) radiation. Nucleic Acids Res. 20: 225-229. doi:10. 1093/nar/20.2.225. PMID:1311069.

Ozer, N.P., and Demirci, A. 2005. Inactivation of Escherichia coli O157:H7 and Listeria monocytogenes inoculated on raw salmon fillets by pulsed UV-light treatment. Int. J. Food Sci. Technol. 40: $1-7$.

Panico, L. 2005. Instantaneous sterilization with pulsed UV light. Workshop: emerging food processing technologies USDA, CSREES. Washington State University. pp. 26-27.

Quesnel, L.B., and Spencer, D. 1985. The effect of visible radiations on the germination and outgrowth of Bacillus spores. Lett. Appl. Microbiol. 1: 33-36.

Roberts, P., and Hope, A. 2003. Virus inactivation by high intensity broad spectrum pulsed light. J. Virol. Methods, 110: 61-65. doi:10.1016/S0166-0934(03)00098-3. PMID:12757921.

Rowan, N.J., MacGregor, S.J., Anderson, J.G., Fouracre, R.A., Mcllvaney, L., and Farish, O. 1999. Pulsed-light inactivation of food-related microorganisms. Appl. Environ. Microbiol. 65: 1312-1315. PMID:10049899.

Sharma, R.R., and Demirci, A. 2003. Inactivation of Escherichia coli O157:H7 on inoculated alfalfa seeds with pulsed ultraviolet light and response surface modelling. J. Food Sci. 68: 1448-1453. doi:10.1111/j.1365-2621.2003.tb09665.x.
Smith, W.L., Lagunas-Solar, M.C., and Cullor, J.S. 2002. Use of pulsed ultraviolet laser light for the cold pasteurisation of bovine milk. J. Food Prot. 65: 1480-1482. PMID:12233862.

Sonenshein, A.L. 2003. Killing of Bacillus spores by high-intensity ultraviolet light. In Sterilization and decontamination using highenergy light. Xenon Corporation, Woburn, Mass. pp. 15-19.

Takeshita, K., Yamanaka, H., Sameshima, T., Fukunaga, S., Isobe, S., Arihara, K., and Itoh, M. 2002. Sterilization effect of pulsed light on various microorganisms. Bokin Bobai, 30: 277-284.

Takeshita, K., Shibato, J., Sameshima, T., Fukunaga, S., Isobe, S., Arihara, K., and Itoh, M. 2003. Damage of yeast cells induced by pulsed light irradiation. Int. J. Food Microbiol. 85: 151-158. doi:10.1016/S0168-1605(02)00509-3. PMID:12810279.

Wallen, R.D., May, R., Rieger, K., Holloway, J.M., and Cover, W.H. 2001. Sterilization of a new medical device using broadspectrum pulsed light. Biomed. Instrum. Technol. 35: 323-330. PMID:11668949.

Wang, T., MacGregor, S.J., Anderson, J.G., and Woolsey, G.A. 2005. Pulsed ultra-violet inactivation spectrum of Escherichia coli. Water Res. 39: 2921-2925. doi:10.1016/j.watres.2005.04. 067. PMID: 15993922.

Wekhof, A. 2000. Disinfection with flash lamp. PDA J. Pharm. Sci. Technol. 54: 264-276. PMID:10927918.

Wekhof, A., Trompeter, F.J., and Franken, O. 2001. Pulsed UVDisintegration (PUVD): a new sterilisation mechanism for packaging and broad medical-hospital applications. In Proceedings of the first International Conference on Ultraviolet Technologies, Washington, DC, USA, 14-16 June 2001. pp. 1-15.

Wuytack, E.Y., Phuong, L.D.T., Aertsen, A., Reyns, K.M., Marquenie, D., De Ketelaere, B., et al. 2003. Comparison of sublethal injury induced in Salmonella enterica serovar Typhimurium by heat and by different nonthermal treatments. J. Food Prot. 66: 31-37. PMID:12540178. 